\title{
Evaluation of Patients' Perspectives on Dental Implants and Bone Graft Surgery: A Questionnaire-based Study
}

\author{
Siddhanth S Jain ${ }^{1}$, Rakesh B Shah ${ }^{2}$, Monika P Surana ${ }^{3}$, Amit D Mahajan ${ }^{4}$, Prachur K Malhotra ${ }^{5}$
}

\begin{abstract}
Aim: To evaluate patients' knowledge and awareness regarding dental implant therapy and bone graft surgeries, various implant techniques; their willingness towards implant surgery and bone-grafting surgeries.

Materials and methods: One hundred sixty patients were included and a pre-typed questionnaire was given to the patients, written in their language and their answers were documented and analyzed.

Result: A total of 160 patients were included. One hundred ten were males and 50 were females. Fifty-six patients were between $20-25$ years of age, 67 patients were between 25-35 years of age and 37 patients were between 35-50 years of age. One hundred twenty-nine patients underwent extraction, 140 patients had missing teeth, 81 patients had periodontal disease, 142 patients were willing for replacement, 113 patients wanted fixed prosthesis, and 95 patients did not know about dental implants. Out of the 65 patients who knew, their source was dentists. One hundred nine patients perceived implants as being costly. One hundred forty-nine patients did not know about bone loss post extraction. Only seven patients knew about bone augmentation surgeries. Eighty-eight patients agreed that good quality bone could significantly improve the treatment outcome. One hundred eight patients wanted more information; however, only 17 patients agreed for implant therapy. Majority of the patients (107) considered financial costs to be the reason to not undergo implant therapy.

Conclusion: This study concluded that patients'knowledge and attitude towards implants was below average as an option for replacing missing teeth. Dentists were the main sources of information. The lack of information about good healthy bone was found to be significant in our group. However, once explained about the various treatment options, their willingness improved significantly. The high treatment cost was a major factor against the willingness of patients and they were reluctant for dental implants. Thus, constructive improvements towards making this treatment modality more affordable and creating more awareness are required.
\end{abstract}

Keywords: Awareness, Bone augmentation, Bone graft surgery, Dental implants, Knowledge, Survey.

International Journal of Prosthodontics and Restorative Dentistry (2019): 10.5005/jp-journals-10019-1224

\section{INTRODUCTION}

$\mathrm{T}$ he problem of edentulism has been present since time immemorial. Various methods and materials were invented for the replacement of missing teeth. From using acrylic teeth used in removable partial denture to fixed partial dentures, the science of replacement of the natural teeth has come a long way to the current field of implantology that has changed the way we treat edentulism in today's dental practice.

Dental implants became the commonly used treatment option since the last 2-3 decades. However, in our country it is still in its preliminary stages. A major cause for this is the lack of awareness among the patients about the possibility of having a permanently replaced dentition.

The decision towards implant therapy-an elective procedure in most patient cases-depends on patients' knowledge and informed consent. Decision making in implant dentistry involves patients' preferences and values, clinicians' heuristics and biases, diagnostic and therapeutic uncertainties, as well as cost considerations (Flemming and Beikler). ${ }^{1}$

Safety, efficacy, effectiveness, and treatment outcome have been described as the four major issues to be considered in dental rehabilitation according to Guckes et al. These days, oral health information gained from the internet may cause misconceptions among patients.

According to Pommer et al., in Austria, there was, over 5 years, a dramatic escalation in the interest of implant treatment. At the time of the second survey (2008), 79\% of participants expressed desires for implant treatment in comparison with $56 \%$ in the first survey
1,3Postgraduate Student, ${ }^{2,4,5}$ Professor

${ }^{1-5}$ Department of Oral and Maxillofacial Surgery, KM Shah Dental College and Hospital, Sumandeep Vidyapeeth, Vadodara, Gujarat, India

Corresponding Author: Monika P Surana, Postgraduate Student, Department of Oral and Maxillofacial Surgery, KM Shah Dental College and Hospital, Sumandeep Vidyapeeth, Vadodara, Gujarat, India, e-mail: monixsurana@gmail.com

How to cite this article: Jain SS, Shah RB, Surana MP, Mahajan AD, Malhotra PK. Evaluation of Patients' Perspectives on Dental Implants and Bone Graft Surgery: A Questionnaire-based Study. Int J Prosthodont Restor Dent 2019;9(1):9-12:

Source of support: Nil

Conflict of interest: None

(2003). The number of dental implants inserted annually worldwide has been estimated to be close to 1 million. ${ }^{2}$

However, in the Indian scenario, the situation is different. The awareness amongst patients regarding the replacement of teeth, their anxieties related to the treatment options need to be addressed.

The lack of information, unrealistic expectations, and high cost of the implant therapy can all be many of the reasons for this disparity. Patients' unmet expectations can negatively influence the treatment outcome, thus identifying patients' expectations is a necessary step to prevent disappointment with the final outcomes. $^{3}$

(O) The Author(s). 2019 Open Access This article is distributed under the terms of the Creative Commons Attribution 4.0 International License (https://creativecommons. org/licenses/by-nc/4.0/), which permits unrestricted use, distribution, and non-commercial reproduction in any medium, provided you give appropriate credit to the original author(s) and the source, provide a link to the Creative Commons license, and indicate if changes were made. The Creative Commons Public Domain Dedication waiver (http://creativecommons.org/publicdomain/zero/1.0/) applies to the data made available in this article, unless otherwise stated. 
Current research in oral implantology, ironically, puts the substantial scientific focus on treatment time reduction, economic analyses, and minimally invasive surgical techniques. However, little is known about factors that motivate patients. Patients' apprehension and fear are considered major barriers to seeking dental implants; the need for supplementary bone grafting procedures may cause additional anxiety.

For professionals, it is vital to assess the patient's level of knowledge and perception of dental implants. Thus keeping these criteria in check, we conducted a study at our institute to evaluate and understand the patients' perspectives on dental implantology.

\section{Materials and methodology}

\section{Materials}

A self-designed, validated questionnaire was given, for evaluating the perspectives on dental implants and bone graft surgeries among the dental patients at KMSDCH, Vadodara, Gujarat, India.

The questionnaire comprised of patients' demographic data. A series of 14 questions printed in English, Hindi, and Gujarati were given to the patients based on their preference of language. Questions evaluated the patients' knowledge on dental implants, their awareness regarding this therapy, the sources through which they became aware of this therapy, their reactions regarding the cost and benefits of the therapy, also any other questions that they may have may be answered verbally to them.

\section{Methodology}

The questionnaires were personally in an attempt to maximize the response given to all the outpatient department (OPD) patients and were collected at the conclusion of the filled forms.

Validated questionnaire result was $86.80 \%$ for this study. The experienced staff of the Department of Oral and Maxillofacial Surgery validated the questionnaire.

Content validation was done for the questionnaire. Reliability was checked using Cronbach's alpha. Overall reliability of the questionnaire in English, Hindi, and Gujarati was 84\%.

\section{Results}

A total of 160 patients were included in this study (Table 1). One hundred ten were males, and 50 were females. As far as age is concerned, 56 were between 20 to 25 years of age, 67 individuals were between 25 to 35 years of age and 37 patients were between 35-50 years of age. One hundred twenty-nine patients were undergoing an extraction procedure. One hundred forty patients had missing teeth. Eighty-one patients had periodontal disease as the reason for tooth extraction, and 142 patients had the inclination to get their missing teeth replaced. One hundred thirteen patients wanted fixed prosthesis. Ninety-five patients had not heard about dental implants (Graph 1). Out of the 65 patients who had heard of implants the majority had heard about them from the dentist (Graph 2). One hundred nine patients had the perception of implants being costly. One hundred forty-nine patients did not know that some amount of bone loss occurs after tooth extraction. Only 7 patients knew about bone augmentation surgeries (Graph 3). Eighty-eight patients agreed that good quality bone can significantly improve the treatment outcome. One hundred eight patients wanted to know more about dental implants however on 17 patients wanted to undergo implant therapy (Graph 4). Majority of the patients (107) considered financial costs to be the reasons to not undergo implant therapy.
Table 1: Questionnaire used in the survey and the results obtained

\begin{tabular}{|c|c|}
\hline \multirow{2}{*}{$\begin{array}{l}\text { Q1: Are you undergoing an extraction } \\
\text { procedure? }\end{array}$} & Yes $=80.6 \%$ \\
\hline & No $=19.37 \%$ \\
\hline \multirow[t]{2}{*}{ Q2: Do you have missing teeth } & Yes $=87.5 \%$ \\
\hline & $\mathrm{No}=12.5 \%$ \\
\hline \multirow[t]{4}{*}{ Q3. Reasons for loss of tooth/teeth? } & Gum disease $=50.6 \%$ \\
\hline & Tooth decay $=41.2 \%$ \\
\hline & Trauma $=5.6 \%$ \\
\hline & Others $=2.5 \%$ \\
\hline \multirow{2}{*}{$\begin{array}{l}\text { Q4. Do you want to replace your } \\
\text { missing teeth? }\end{array}$} & Yes $=88.75 \%$ \\
\hline & No $=11.25 \%$ \\
\hline \multirow[t]{2}{*}{$\begin{array}{l}\text { Q5. If Yes, then would you like to } \\
\text { replace them with: }\end{array}$} & $\begin{array}{l}\text { Removable dentures = } \\
29.37 \%\end{array}$ \\
\hline & $\begin{array}{l}\text { Fixed artificial teeth = } \\
70.6 \%\end{array}$ \\
\hline \multirow[t]{2}{*}{ Q6. Have you heard of dental implants } & Yes $=40.6 \%$ \\
\hline & No $=59.3 \%$ \\
\hline \multirow{5}{*}{$\begin{array}{l}\text { Q7. If Yes, then how do you know } \\
\text { about implants? }\end{array}$} & Internet $=18.75 \%$ \\
\hline & Newspaper $=30.62 \%$ \\
\hline & Dentist $=46.87 \%$ \\
\hline & Friends $=1.25 \%$ \\
\hline & Other sources $=2.5 \%$ \\
\hline \multirow{5}{*}{$\begin{array}{l}\text { Q8. Are any of the following } \\
\text { statements true, based on your } \\
\text { understanding of dental implants: }\end{array}$} & $\begin{array}{l}\text { Implants are costly = } \\
68.12 \%\end{array}$ \\
\hline & Difficult to place $=3.75 \%$ \\
\hline & $\begin{array}{l}\text { Long duration of } \\
\text { treatment }=18.75 \%\end{array}$ \\
\hline & Risk of surgery $=5.6 \%$ \\
\hline & $\begin{array}{l}\text { Damage of healthy bone/ } \\
\text { teeth }=3.75 \%\end{array}$ \\
\hline \multirow{2}{*}{$\begin{array}{l}\text { Q9. Do you know that some amount of } \\
\text { healthy bone is lost once a tooth is } \\
\text { extracted? }\end{array}$} & Yes $=6.8 \%$ \\
\hline & No $=93.125 \%$ \\
\hline \multirow{2}{*}{$\begin{array}{l}\text { Q10. Do you know that there are } \\
\text { various surgeries that can be } \\
\text { done to preserve or increase the } \\
\text { level of bone in your jaws? }\end{array}$} & Yes $=4.3 \%$ \\
\hline & $\mathrm{No}=95.6 \%$ \\
\hline \multirow{2}{*}{$\begin{array}{l}\text { Q11. Do you know that good quality } \\
\text { of bone can significantly improve } \\
\text { the outcome of dental Implant } \\
\text { therapy }\end{array}$} & Yes $=55.5 \%$ \\
\hline & $\mathrm{No}=45.5 \%$ \\
\hline \multirow{2}{*}{$\begin{array}{l}\text { Q12. Would you be interested in } \\
\text { knowing more about dental } \\
\text { implants }\end{array}$} & Yes $=67.5 \%$ \\
\hline & $\mathrm{No}=32.5 \%$ \\
\hline \multirow{2}{*}{$\begin{array}{l}\text { Q13. Would you be interested in } \\
\text { Replacing your missing teeth with } \\
\text { Dental Implants? }\end{array}$} & Yes $=10.6 \%$ \\
\hline & $\mathrm{No}=89.37 \%$ \\
\hline \multirow[t]{4}{*}{ Q14. If No, then it is due to: } & $\begin{array}{l}\text { Personal reasons }= \\
10.62 \%\end{array}$ \\
\hline & $\begin{array}{l}\text { Financial reasons }= \\
66.87 \%\end{array}$ \\
\hline & $\begin{array}{l}\text { Long duration of } \\
\text { treatment }=21.25 \%\end{array}$ \\
\hline & $\begin{array}{l}\text { Not convinced for bone } \\
\text { graft surgeries }=1.25 \%\end{array}$ \\
\hline
\end{tabular}




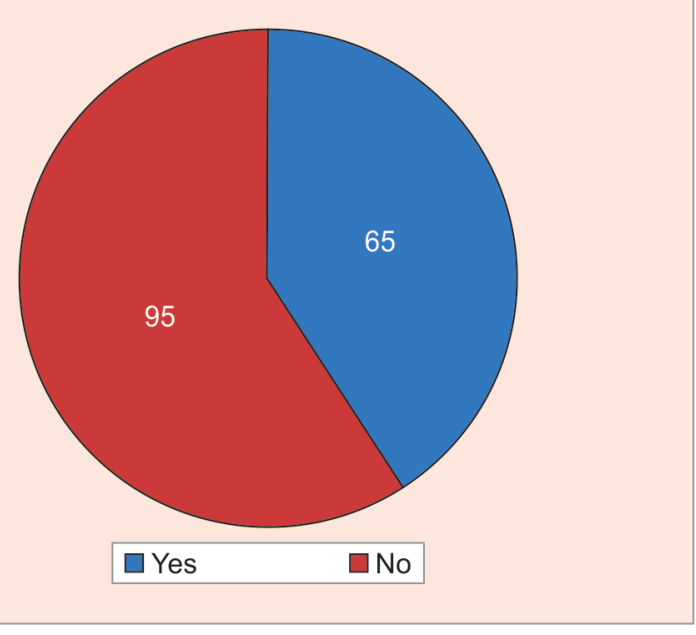

Graph 1: Have you heard of dental implants?

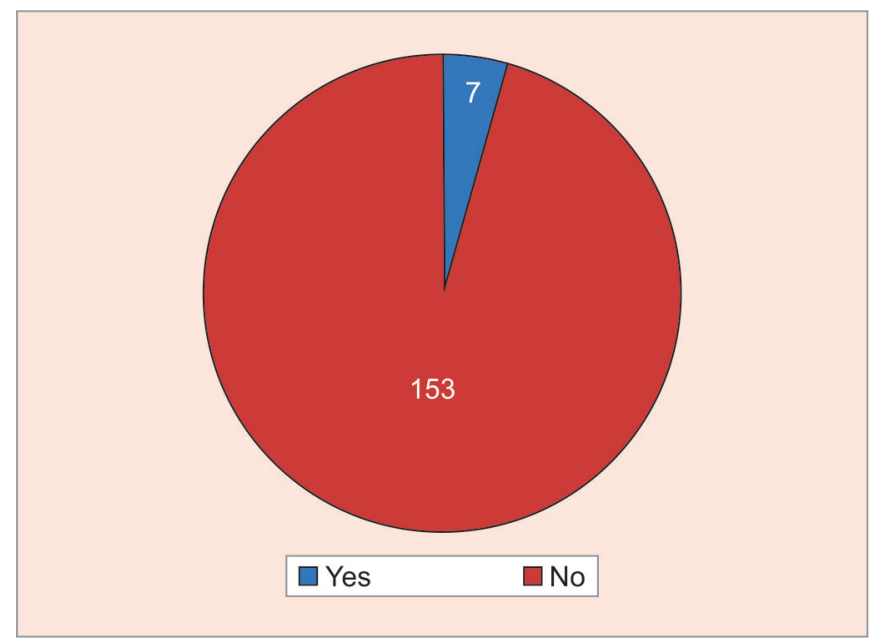

Graph 3: Do you know that there are various surgeries that can be done to preserve or increase the level of bone in your jaws?

\section{Discussion}

Efficacy and outcome of dental implants have been confirmed by various studies conducted ever since the introduction of dental implants. Initially, the dental implants were used with the aim of restoration of edentulous ridges. But with time, their use has entered a wide range of spectrum including prosthetic treatment of partially edentulous areas. This has led to wide acceptance of dental implants throughout the world. ${ }^{4-6}$

Therefore, in today's scenario, it is important to know the knowledge and awareness of patients towards the use of dental implants for treatment. Knowing about the patients attitude and knowledge about dental implants can help so that any negative factors and misconceptions regarding dental implants in the patients mind can be removed.

Therefore, this study was conducted among the patients reporting to our Department of Oral and Maxillofacial Surgery to assess the awareness about dental implants. The survey was based on a simple questionnaire form, which was given to patients coming to our OPD.

In the present study, out of a total of 160 patients, $68.75 \%$ were males and rest were females. Majority of the subjects were between 25-35 years of age.

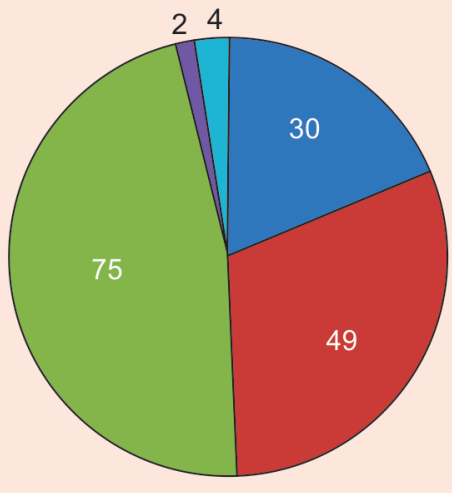

$\square$ Internet $\square$ Newspaper advertisements $\square$ Dentist $\square$ Friends

Graph 2: If yes, then how do you know about implants?

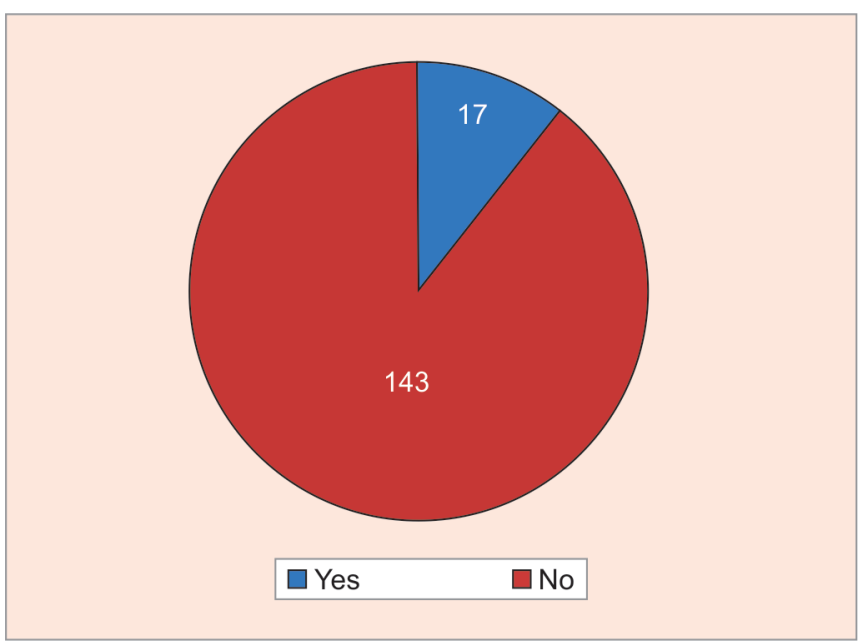

Graph 4: Would you be interested in replacing your missing teeth with dental implants?

About $80.6 \%$ of the study population had reported for the extraction of one of their teeth (Table 1). Almost $87.5 \%$ of the patients had a missing tooth; this feature was common with a study conducted by Kola et al. ${ }^{3}$ who had a study population that consisted of $99 \%$ patients having a missing tooth. A most common reason for the loss of a tooth was dental caries, however, in our study, we found that dental caries consisted of $41.2 \%$ of the population and that periodontal disease was the majority with $50.6 \%$ people affected.

A total of $88.75 \%$ of the patients had the inclination to get their missing teeth replaced, this correlated to the study conducted by Kola et al. ${ }^{3}$ where $99 \%$ of the subjects wanted to get their missing teeth, if any, restored. This shows patients concern for their functional and aesthetic rehabilitation. In our study, $70.6 \%$ of the patients wanted to replace their missing teeth with the fixed prosthesis in comparison with only $29.37 \%$ wanting to replace them with a removable prosthesis.

Salonen et al.7 reported a low rate of awareness (29\%) of dental implant treatment procedures among a given population in Finland. Similarly, in our study only about $40.6 \%$ of patients were aware of dental implants. Although a major percentage preferred removable prosthesis for the replacement of missing teeth, the majority of the subjects were well aware of the implants treatment available these days. 
One of the important aspects of awareness of implants is the source of knowledge. Majority of the subjects gained information about implant restorative dentistry through their dentist (46.87\%). This correlated with studies conducted by many authors such as Suprakash et al..$^{8}$ who reported $58.4 \%$ for dentists being the primary source of information for the patients. Zimmer et al. ${ }^{9}$ in their survey observed that more than $75 \%$ of the patients gained knowledge through media whereas dentists formed a very small group of population spreading awareness.

To assess the knowledge and understanding of the patients on dental implantology we asked them the following set of questions. We found that the majority of patients had the perception of Implants being very expensive $68.12 \%$. This correlated with plenty of studies by Kola et al., ${ }^{3}$ Suprakash et al., ${ }^{8}$ etc. The long duration of treatment (18.75\%) was the second most common understanding that the patients had on dental implants. Next, to assess the patients' understanding of bone physiology, we asked them about the loss of healthy bone post extraction and found that most patients $(93.125 \%)$ did not know that some amount of bone resorption does take place post dental extraction. Regarding their knowledge on bone augmentation procedures, the majority of patients were unaware (95.6\%); however, the majority of them $(55.5 \%)$ did agree that healthy bone can improve the treatment outcome.

Finally, $67.5 \%$ of the patient population group showed an increased interest in knowing more about dental implants.

However, when asked about getting their missing teeth replaced with dental implants, we found a majority of the $89.37 \%$ of the patients were still not willing for dental implant therapy. This was in stark contrast with other studies conducted by authors like Kola et al. ${ }^{3}$ where $99 \%$ of their patients were willing for implant therapy.

Upon further questioning, the majority of them were still apprehensive about implant therapy primarily because of the cost factor. Financial Reason consisted of $66.87 \%$ of the reasons to not go in for dental implant therapy. Our patient population consisted mainly of a low to a middle-income group of patients, coming to our institute. Hence for such a patient population, the cost factor plays a major role in the decision making as far as the dental treatments are considered. The long duration of treatment that was initially $18.75 \%$ was still the second most common reason to not undergo implant therapy (21.25\%).

\section{Conclusion}

The present study was conducted on the patients from various age groups, all reporting with an inherent complain of missing teeth. It was concluded that patients' knowledge and attitude towards implants was below average as an option for replacing missing teeth.

These patients that although were convinced to get fixed artificial teeth were found to be reluctant towards choosing dental implants as a choice of replacement for their missing teeth. Dentists were the main sources of information regarding dental implants among all participants, although newspaper advertisements the social circles of the patients also play an important role in spreading knowledge and information regarding the dental implants towards the patients.

It was also found that the lack of information about the requirement of good healthy bone for the success of dental implants was found to be significant in our dental patient group. However, it was found that once the patients were explained about the various treatment options regarding the improvement of their existing bone architecture, they seemed to approve the procedure and their willingness to undergo the bone augmentation procedures improved significantly.

The high treatment cost of the implants is one of the major factors against the willingness of patients to undergo this treatment. It also showed the need for providing more general and correct information to the patients about this treatment modality. We found that despite the plentiful information we provided to our patients regarding the treatment, they were still reluctant to undergo the treatment mainly due to its high cost and long duration.

Thus, constructive improvements have to be made towards making this treatment modality more affordable to the common public as well as creating more awareness amongst the people is required.

\section{References}

1. Hof M, Tepper G. Patients' perspectives on dental implant and bone graft surgery: questionnaire based interview study. Clin Oral Impl Res.2014;25:42-45.

2. Pommer B, Zechner W. Progress and trends in patients' mindset on dental implants. I: level of information, sources of information and need for patient information. Clin Oral Implants Res 2011;22: 223-229.

3. Kola MZ, Alasqah MN. Public awareness, information sources and evaluation of oral implant treatment in Alkharj town (Kingdom of Saudi Arabia) - A survey based study. J Adv Med Dent Scie Res 2016;4(6):114-120.

4. The Mc Gill consensus statement on over dentures. Quintessence Int. 2003; 34, p. 78-79.

5. Naert I, Koutsikakis G, Duyck J, Quirynen M, Jacobs R, van Steenberghe D. Biologic outcome of implant-supported restorations in the treatment of partial edentulism. Part I: a longitudinal clinical evaluation. Clin Oral Implants Res. 2002;13:381-389

6. Albrektsson T. A multicenter report on osseointegrated oral implants. J Prosthet Dent 1988;60:75-84

7. Salonen MA. Assessment of states of dentures and interest in implant retained prosthetic treatment in 55-year-old edentulous. Oral Epidemiol 1994; 22:130-135.

8. Suprakash B, Ahammed ARY, Thareja A,et al. Knowledge and attitude of patients toward dental implants as an option for replacement of missing teeth. J Contemp Dent Pract 2013;14(1): $115-118$.

9. Zimmer CM, Zimmer WM. Public awareness and acceptance of dental implants. Int J Oral Maxillofac Implants 1992; 7:228-232. 